\title{
Heteroplasmic Variants of Mitochondrial DNA in Atherosclerotic Lesions of Human Aortic Intima
}

\author{
Igor A. Sobenin ${ }^{1,2,3, *,+} \mathbb{D}$, Andrey V. Zhelankin ${ }^{4,+} \mathbb{D}$, Zukhra B. Khasanova ${ }^{1}$, Vasily V. Sinyov ${ }^{1,2}$ \\ Lyudmila V. Medvedeva ${ }^{5}$, Maria O. Sagaidak ${ }^{6,7}$, Vsevolod J. Makeev ${ }^{6,7,8}{ }^{(D)}$, \\ Kira I. Kolmychkova ${ }^{9}{ }^{\mathbb{D}}$, Anna S. Smirnova ${ }^{9}$, Vasily N. Sukhorukov ${ }^{1,10}{ }^{\mathbb{D}}$, Anton Y. Postnov ${ }^{1,10}$, \\ Andrey V. Grechko ${ }^{11}$ and Alexander N. Orekhov ${ }^{9,10} \mathbb{D}$ \\ 1 Institute of Experimental Cardiology, National Medical Research Center of Cardiology, \\ 121552 Moscow, Russia \\ 2 Institute of General Pathology and Pathophysiology, 125315 Moscow, Russia \\ 3 Research Institute of Threpsology and Healthy Longevity, Plekhanov Russian University of Economics, \\ 115093 Moscow, Russia \\ 4 Federal Research and Clinical Center of Physical-Chemical Medicine, 119435 Moscow, Russia \\ 5 Federal Research Center of Transplantology and Artificial Organs, 123182 Moscow, Russia \\ 6 Vavilov Institute of General Genetics, 117971 Moscow, Russia \\ 7 Moscow Institute of Physics and Technology, Dolgoprudny, 141701 Moscow Region, Russia \\ 8 Engelhardt Institute of Molecular Biology, 119991 Moscow, Russia \\ 9 Institute for Atherosclerosis Research, Skolkovo Innovation Center, 143026 Moscow, Russia \\ 10 Research Institute of Human Morphology, 117418 Moscow, Russia \\ 11 Federal Scientific Clinical Center for Resuscitation and Rehabilitation, 141534 Moscow Region, Russia \\ * Correspondence: igor.sobenin@gmail.com; Tel.: +7-926-359-0050 \\ + These authors contributed equally to this work.
}

Received: 12 July 2019; Accepted: 3 September 2019; Published: 6 September 2019

\begin{abstract}
Mitochondrial dysfunction and oxidative stress are likely involved in atherogenesis. Since the mitochondrial genome variation can alter functional activity of cells, it is necessary to assess the presence in atherosclerotic lesions of mitochondrial DNA (mtDNA) heteroplasmic mutations known to be associated with different pathological processes and ageing. In this study, mtDNA heteroplasmy and copy number $(\mathrm{mtCN})$ were evaluated in the autopsy-derived samples of aortic intima differing by the type of atherosclerotic lesions. To detect mtDNA heteroplasmic variants, next generation sequencing was used, and $\mathrm{mtCN}$ measurement was performed by qPCR. It was shown that mtDNA heteroplasmic mutations are characteristic for particular areas of intimal tissue; in 83 intimal samples 55 heteroplasmic variants were found; mean minor allele frequencies level accounted for 0.09 , with $12 \%$ mean heteroplasmy level. The $\mathrm{mtCN}$ variance measured in adjacent areas of intima was high, but atherosclerotic lesions and unaffected intima did not differ significantly in $\mathrm{mtCN}$ values. Basing on the ratio of minor and major nucleotide mtDNA variants, we can conclude that there exists the increase in the number of heteroplasmic mtDNA variants, which corresponds to the extent of atherosclerotic morphologic phenotype.
\end{abstract}

Keywords: atherosclerosis; mitochondrial DNA mutations; next generation sequencing; mitochondrial DNA copy number; unaffected intima; fatty infiltration; fatty streaks; lipofibrous plaque; fibrous plaque

\section{Introduction}

The emergence and development of atherosclerotic lesions in the arterial wall are known to occur locally and even focally. The focality of atherosclerotic lesions can be explained by the differences 
in hemodynamic stress in different parts of the vessel, the local changes in the permeability of the vascular endothelium, and the presence of morphologically and functionally distinct subpopulations of cells able to form local clusters under the endothelial lining [1-3]. The alterations in the structure of the mitochondria, mitochondrial dysfunction, and oxidative stress are frequently observed in atherosclerotic lesions [4,5]. Reactive oxygen species (ROS) generated by mitochondria are involved in processes that contribute to the progression of atherosclerotic lesions [6]. Oxidative stress in mitochondria is considered to be the cause of increased mutation rate in mitochondrial DNA (mtDNA), that is 6-17 times higher compared to the nuclear DNA. The presence of multiple copies of mtDNA in single cell explains the phenomenon of mtDNA heteroplasmy, i.e., the variable proportion of normal and mutant mtDNA copies within the cell or tissue [7-9]. Recent studies have confirmed the presence of mtDNA heteroplasmy in various types of human tissues; there are heteroplasmic mutations that are accumulated with ageing [10]. The assessment of mtDNA heteroplasmic mutation load, as well as mtDNA copy number $(\mathrm{mtCN})$ is a plausible way to explain the focality of atherosclerotic lesions [11-14]. Heteroplasmic mtDNA mutations are known to be associated with different age-related diseases [7,15-17]. The presence of mtDNA heteroplasmy, which is conventionally regarded as the molecular basis for mitochondrial cytopathies, have been found also in healthy individuals without any symptoms of such diseases [18]. For a number of heteroplasmic mtDNA mutations, the accumulation of mutant mtDNA copies in specific tissues have been proved [10]. Possibly, heteroplasmic mtDNA mutations are of somatic origin, since the activity of mitochondrial function and ROS production vary significantly between different types of tissues [19]; however, the significant part of heteroplasmic mtDNA mutations, or variants, may be inherited by maternal line [20,21]. Pathogenic mtDNA mutations affect respiratory chain functioning, usually forming the mosaic structure of its deficiency. Cells possessing the level of heteroplasmy exceeding a certain threshold, exhibit mitochondrial dysfunction, whereas in the adjacent cells with lower mutational load the respiratory chain remains fully functional $[4,8,22-24]$. A similar pattern can be observed in atherosclerosis: the normal (unaffected) areas of arterial wall exist side by side with different types of atherosclerotic lesions, and mtDNA mutational load exhibits mosaic structure, as well $[25,26]$. The recent studies based on the use of high-throughput sequencing technologies have demonstrated that mtDNA heteroplasmy occurs commonly and usually has the frequency rate of about $2 \%[27,28]$. This study was undertaken to test the hypothesis that the frequency rate of mtDNA heteroplasmic mutations increases in atherosclerotic lesions, thus providing the mechanistic explanation of atherosclerosis focal progression.

\section{Materials and Method}

\subsection{Human Aortic Intimal Tissue Autopsy Samples}

A total of 7 autopsy samples of thoracic aorta were taken within 48 post-mortem hours from 7 different subjects. The study protocol was approved by the Ethics Committee of the Institute for Atherosclerosis Research, Moscow (protocol No. 7 of 17 October 2017). Gender, age and pathological diagnosis of subjects are shown in Table 1.

The vessels were opened longitudinally and washed with ice-cold phosphate buffered saline, $\mathrm{pH}=7.6$. Each section contained normal (unaffected) areas of aortic intima, as well as 5 different types of atherosclerotic lesions: Fatty infiltrations (type I lesions, FI), fatty streaks (type II lesions, FS), lipofibrous plaques (type Va lesions, LFP) and fibrous plaques (type Vc lesions, FP). To determine the type of lesion, the fragments of aortic intima were examined macroscopically and were classified in accordance with the classification of the Atherosclerosis Council of the American Heart Association [29,30]. Aortic intima was mechanically separated from medial layer, and 11-12 samples of intimal tissue sizing up to $0.25 \mathrm{~cm}^{2}$ were carved from each autopsy sample. Additionally, the tissue samples from skeletal muscle (SM), myocardial muscle (MM), liver (LIV), and spleen (SPL) were taken at each autopsy, except for the case as_01. Thus, a total of 83 aortic intimal samples and 24 samples from other tissues were collected for the study and kept at $-80{ }^{\circ} \mathrm{C}$ prior to DNA extraction. 
Table 1. Pathologic characteristics of aortic intima autopsy samples.

\begin{tabular}{|c|c|c|c|c|c|c|c|c|}
\hline \multirow{2}{*}{ Case No. (ID) } & \multirow{2}{*}{ Age } & \multirow{2}{*}{ Gender } & \multirow{2}{*}{ Pathologic Diagnosis } & \multicolumn{5}{|c|}{ The Number of Tissue Samples } \\
\hline & & & & $\mathbf{N}$ & FI & FS & LFP & FP \\
\hline as_01 & 85 & $\mathrm{f}$ & macrofocal atherosclerosis & 2 & 1 & 2 & 3 & 3 \\
\hline as_02 & 83 & $\mathrm{~m}$ & $\begin{array}{l}\text { pulmonary heart disease, } \\
\text { thromboembolia of small pulmonary } \\
\text { arteries, macrofocal cardiosclerosis } \\
\text { pulmonary heart disease, bilateral }\end{array}$ & 2 & 2 & 2 & 3 & 3 \\
\hline as_03 & 86 & $\mathrm{f}$ & $\begin{array}{l}\text { confluent bronchopneumonia, diffuse } \\
\text { microfocal cardiosclerosis }\end{array}$ & 2 & 2 & 2 & 3 & 3 \\
\hline as_04 & 87 & $\mathrm{f}$ & $\begin{array}{l}\text { pulmonary artery thromboembolia, } \\
\text { macrofocal cardiosclerosis }\end{array}$ & 2 & 3 & 3 & 2 & 2 \\
\hline as_05 & 60 & $\mathrm{~m}$ & $\begin{array}{c}\text { gastrorrhagia } \\
\text { diffuse microfocal cardiosclerosis }\end{array}$ & 3 & 2 & 2 & 2 & 3 \\
\hline as_06 & 83 & $\mathrm{~m}$ & $\begin{array}{l}\text { cardiohepatic insufficiency, right-focal } \\
\text { abscessed confluent pneumonia }\end{array}$ & 2 & 2 & 2 & 3 & 3 \\
\hline as_07 & 83 & $\mathrm{~m}$ & $\begin{array}{l}\text { right kidney cancer, cancerous cachexia, } \\
\text { macrofocal atherosclerosis }\end{array}$ & 2 & 3 & 2 & 2 & 3 \\
\hline \multicolumn{3}{|c|}{ Total number of samples } & & 15 & 15 & 15 & 18 & 20 \\
\hline
\end{tabular}

$\mathrm{m}$-male; $\mathrm{f}$-female; $\mathrm{N}$-normal (unaffected) intima; FI—fatty infiltration; FS—fatty streak; LFP—lipofibrous plaque; $\mathrm{FP}-$ fibrous plaque.

\subsection{DNA Extraction and $m t D N A$ Enrichment}

Each tissue sample was homogenized in liquid nitrogen, and total genomic DNA was extracted from $50 \mathrm{mg}$ of sample using Qiagen DNEasy kit (QIAGEN, Germantown, MD, USA). Enrichment of mtDNA was carried out by long-range PCR with high-fidelity Q5 polymerase (New England Biolabs, Ipswich, MA, USA) and two specific primer sets (Set 1: ACGGGCTCA CATCACCCCATAA and GTACGGCCAGGGCTATTGGT; Set 2: ACAACTAACCTCCTCGGACTCCT and CVTGGCTGGCACGAAATTGACC), with amplification of two overlapping mtDNA fragments with the length of 8378 and 8702 b.p., respectively; the overlappings were at positions 623-893 (covers the end of tRNA-phenylalanine coding sequence, minor H-strand promoter, the beginning of 12S RNA coding sequence), and at positions 8767-9001 (covers the part of ATP synthase F0 subunit 6 coding sequence). Amplification included 33 cycles and was set up in accordance with recommendations on the use of Q5 polymerase. The lengths of obtained fragments were confirmed by electrophoresis of the whole sample in $1 \%$ agarose gel. Target large fragments (bands in 8-10 kB region) were cleaned up from PCR mix components by elution from agarose gel on columns using specific elution kit (Evrogen, Moscow, Russia). Concentration of DNA fragments was measured by spectrophotometry using NanoDrop nanophotometer (Implen, München, Germany), and both of mtDNA-enriched fragments were pooled for each sample in equal weight amounts in single tube.

\subsection{Whole mtDNA Sequencing}

Roche 454 GS Junior Titanium System was used for high-throughput sequencing of mtDNA. Five hundred nanogram of the enriched mtDNA fraction was taken for DNA libraries preparation and further sequencing. «Shotgun» DNA libraries were made by fragmentation of amplicons with nitrogen under pressure of 2.1 bar and ligation of specific sequencing adapters (GS MID Adaptors Kit, Roche Applied Science, Madison, WI, USA). Sequencing workflow was performed according to the manufacturer's recommendations using appropriate instruments and reagents. The following parameters were achieved: mean reading length, $458 \mathrm{bp}$; the mean number of readings, 18,734; the mean number of nucleotides read in one sample, 8.65 million b.p. The mean percent of mapped readings accounted for $93 \%$. To detect heteroplasmic variants of mtDNA, sequences with more than 300 -fold coverage of the mitochondrial genome were taken, thus allowing reliable detection of variants with a level of heteroplasmy of at least $1 \%$ in the presence of direct and reverse readings of the mutant allele. 


\subsection{Measurement of mtDNA Copy Number}

MtDNA copy number $(\mathrm{mtCN})$ was measured by qPCR with three primer sets according to Venegas and Halberg [31] by comparative ct $\left(2^{-\Delta \Delta C T}\right)$ method [32], using SYBR Green Supermix (Evrogen, Moscow, Russia) and BioRad CFX96 Touch Real-Time PCR Detection System (BioRad, Hercules, CA, USA). Total genomic DNA extracted from tissue samples was taken in amount of 25 ng per $25 \mu \mathrm{L}$ reaction volume. Variations between 3 replicative measurements did not exceed 0.5 cycles. MtCN was calculated as a ratio between mtDNA and nucDNA copies, with the formula $2^{(-\Delta \mathrm{Cq})}$, where $\Delta \mathrm{Cq}=\mathrm{Cq}$ (nDNA set) $-\mathrm{Cq}_{\text {mean }}$ (mtDNA set; mtDNA alternative set).

\subsection{Bioinformatical and Statistical Analysis of Sequencing Data}

Since the use of 454 technology for sequencing is characterized by limitations when sequencing homopolymers, the processing of the data should be performed with accurate handling and filtration of reads avoiding artefacts in heteroplasmy detection [33]. Therefore, $5^{\prime}$-adaptor sequences were cut from the reads using Cutadapt software [34]. Filtration by quality was performed with Trimmomatic [35]. Reads shorter than 30 b.p. were eliminated with the quality threshold of 20 (SLIDINGWINDOW option with window size 3 , required quality 20, minimal read length 30 ). Then, the reads were mapped on Homo sapiens mitochondrion complete genome sequence (NCBI Reference Sequence, GenBank accession number NC_012920.1) [36] with the use of BWA-MEM software [37]. To avoid simultaneously mapping of reads in different places, reads with MAPQ $<50$ were excluded from further consideration. SNPs were obtained using Bcf-tools and Samtools, and annotated in Annovar software [38,39].

Extraction of heteroplasmic SNPs from the general SNP pool was performed with the following criteria:

- both of two variant nucleotides at the SNP site should be presented in the reads mapped to rCRS;

- the coverage of heteroplasmic site should be within the limit of $0.5-2.0$-fold of the mean coverage depth;

- SNPs on homopolymeric sites were excluded from further analysis;

- heteroplasmic site should be covered with forward and reverse reads.

Further, heteroplasmies which did not satisfy the last condition, but were found in the same tissue samples of the same individual and in the same position, were additionally analyzed. For minor allele frequencies (MAFs) of such a pair of heteroplasmies binominal test was performed. If p-value exceeded 0.95 , the heteroplasmy was considered assuming that in the same type of lesion heteroplasmies can match and its detection is not a sequencing error. MAFs for heteroplasmic variants were calculated as a ratio of the number of minor nucleotide variant and the total number of nucleotides in the particular position of mtDNA. Wilcoxon signed-rank test was used to obtain values of significance between mean MAFs of the heteroplasmies between individuals and between unaffected aortic tissue and early changes ( $\mathrm{N}$ and FI) and evident atherosclerotic lesions (FS, LFP, and FP). Chi-squared test was used for verification of the total number of heteroplasmies in unaffected and atherosclerotic tissue.

The results were considered as significant with the criterion of $p$-value $<0.05$. Diagram and plot creation, statistical analysis and data processing were performed with SciPy [40], pandas [41], Matplotlib [42], and seaborn [43] software. MtDNA mutations were named according to HGVS nomenclature [44]. RefSeq NC_012920.1 prefix was used in the full names of all mutations.

\section{Results}

\subsection{Heteroplasmic Variants of $m t D N A$}

The total of 55 cases of heteroplasmy that satisfied all required criteria of selection were found in $27 \mathrm{mtDNA}$ positions, with more than $90 \%$ of all sequencing reads being mapped on Homo sapiens mitochondrion complete genome sequence. Heteroplasmic variants were found in all male and female 
individuals analyzed. Distribution of the number and frequency of heteroplasmies by mtDNA genes are shown in Figures 1 and 2.

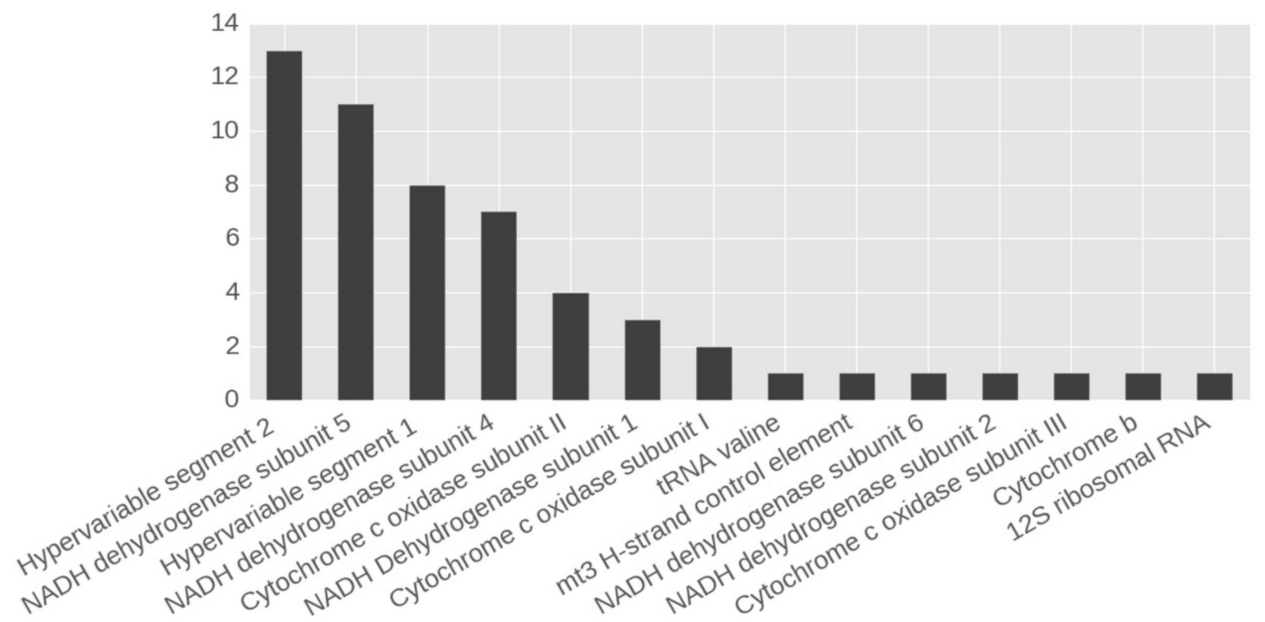

Figure 1. The number of heteroplasmic variants found in regions and genes of mitochondrial DNA (mtDNA).

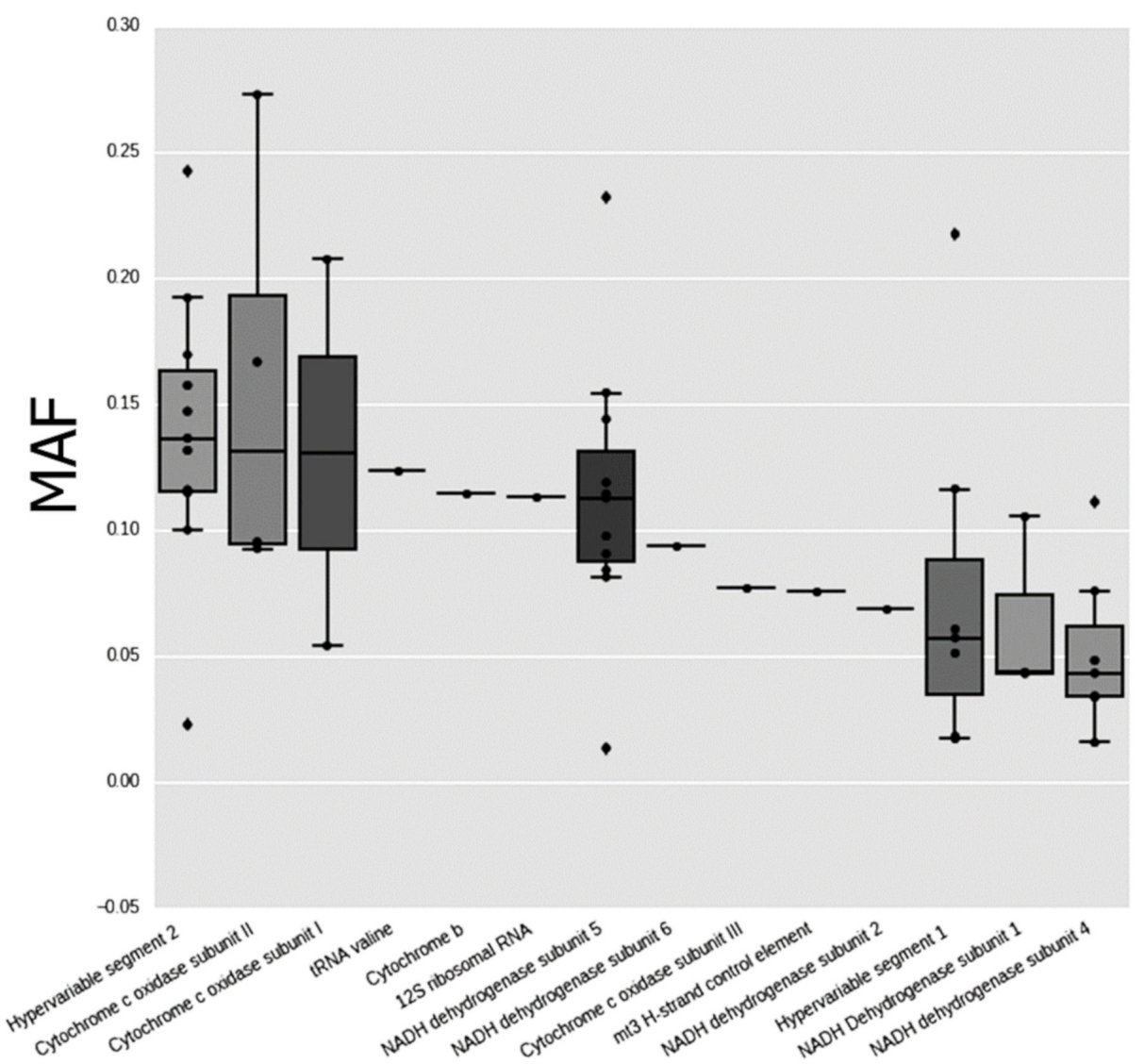

Figure 2. The boxplot showing minor allele frequencies (MAF) distribution of heteroplasmic variants in regions and genes of mtDNA. Circles, the cases falling into observed distribution; diamonds, outliners.

The most cases of heteroplasmy were found in hypervariable segment (HVS) and in NADH-dehydrogenase subunits 4 and 5. Interestingly, only 2 heteroplasmic variants were found in different individuals ( $\mathrm{m} .152 \mathrm{~T}>\mathrm{C}$ in 3 cases, and m.16304T $>\mathrm{C}$ in 2 cases), and both these variants were located in HVS. All other heteroplasmic variants were unique for each case. The final set of 
all heteroplasmic variants and their location in mtDNA are shown in Figure 3. This information is provided also in Table 2 and Table S1 (Supplementary Materials).

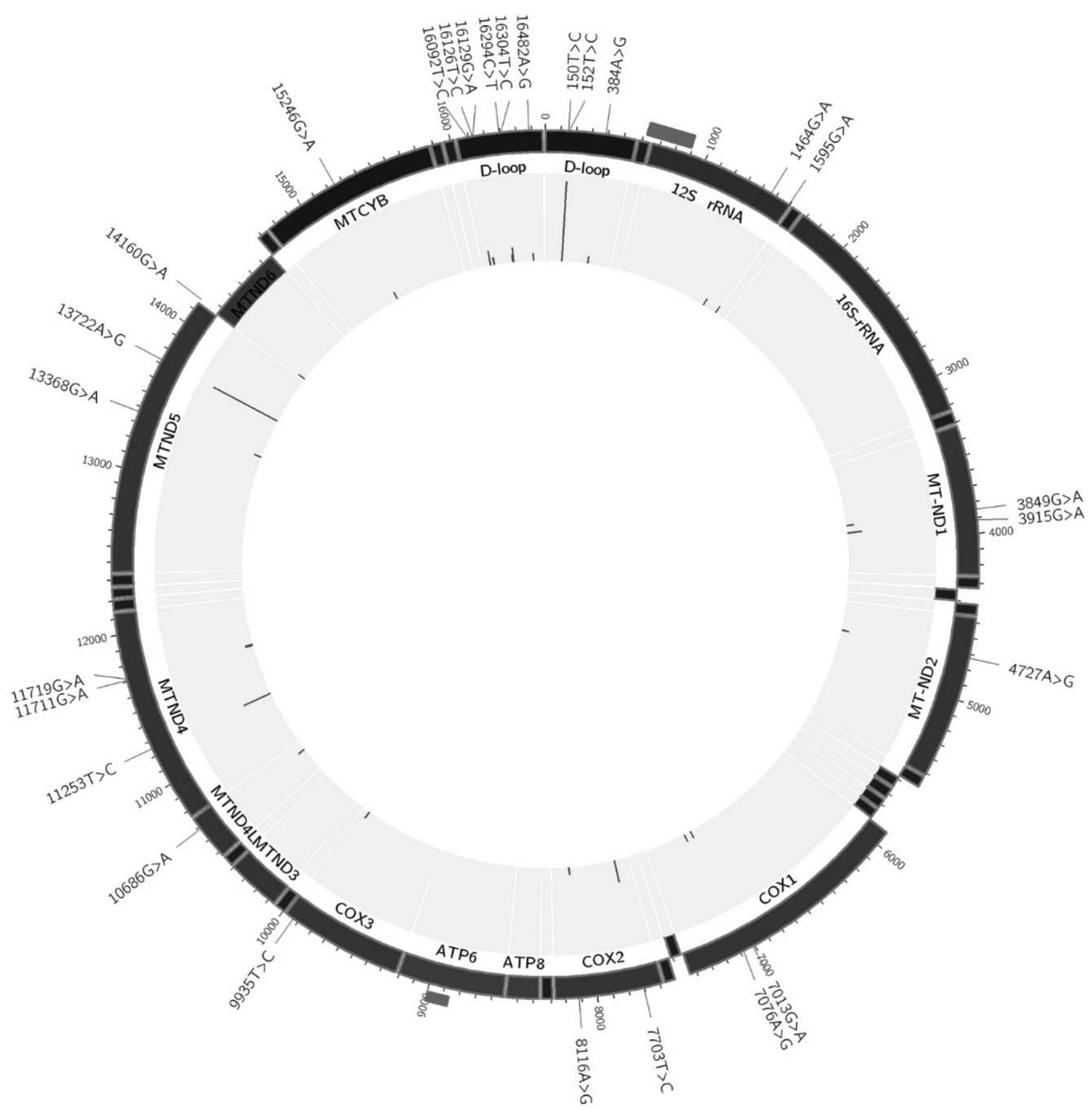

Figure 3. MtDNA map of heteroplasmic variants found in the study. Dark grey rectangles outside mark overlapping mtDNA fragments during mtDNA enrichment at positions 623-893 and 8767-9001; none of detected variants were located within these ranges.

The mean MAF values of heteroplasmic variants were growing from unaffected aortic tissue to fibrous and lipofibrous plaques (Figure 4). The chi-square test of independence was performed for the contingency table (Table 3 ).

The resulting $p$-value was $2.72 \times 10^{-10}$, what meant that the hypothesis of MAF independence from the lesion type was to be rejected. Wilcoxon signed-rank test was performed for the data given in Table 4 , and $p$-value was 0.018 , thus demonstrating the significance of MAF shift from unaffected tissue samples to atherosclerotic lesions. 
Table 2. Heteroplasmic mtDNA variants found in the aortic intimal tissue.

\begin{tabular}{|c|c|c|c|c|c|c|}
\hline Position & Gene/Region & Nucleotide Change & $\begin{array}{l}\text { Mutation Type (for Protein-Coding } \\
\text { Genes) and Aminoacid Change }\end{array}$ & $\begin{array}{c}\text { Total Number of } \\
\text { Hetero-Plasmy Cases }\end{array}$ & Mean MAF & SD \\
\hline 150 & Hypervariable segment 2 & $\mathrm{C}>\mathrm{T}$ & - & 2 & 0.0175 & 0.0078 \\
\hline 152 & Hypervariable segment 2 & $\mathrm{~T}>\mathrm{C}$ & - & 11 & 0.1528 & 0.0407 \\
\hline 384 & $\mathrm{mt} 3 \mathrm{H}$-strand control element & $A>G$ & - & 1 & 0.0760 & \\
\hline 1464 & $12 \mathrm{~S}$ ribosomal RNA & $\mathrm{G}>\mathrm{A}$ & - & 1 & 0.1130 & \\
\hline 1595 & tRNA valine & $\mathrm{G}>\mathrm{A}$ & - & 1 & 0.1240 & \\
\hline 3849 & NADH Dehydrogenase subunit 1 & $\mathrm{G}>\mathrm{A}$ & syn:L-L & 1 & 0.1050 & \\
\hline 3915 & NADH Dehydrogenase subunit 1 & $\mathrm{G}>\mathrm{A}$ & syn:G-G & 2 & 0.0430 & 0.0000 \\
\hline 4727 & NADH dehydrogenase subunit 2 & $A>G$ & syn:M-M & 1 & 0.0690 & \\
\hline 7013 & Cytochrome c oxidase subunit I & $\mathrm{G}>\mathrm{A}$ & syn:T-T & 1 & 0.0540 & \\
\hline 7076 & Cytochrome c oxidase subunit I & $A>G$ & syn:G-G & 1 & 0.2070 & \\
\hline 7703 & Cytochrome c oxidase subunit II & $\mathrm{T}>\mathrm{C}$ & non-syn:Y-H & 3 & 0.1183 & 0.0422 \\
\hline 8116 & Cytochrome c oxidase subunit II & $A>G$ & syn:G-G & 1 & 0.2730 & \\
\hline 9935 & Cytochrome c oxidase subunit III & $\mathrm{T}>\mathrm{C}$ & syn:H-H & 1 & 0.0770 & \\
\hline 10686 & NADH dehydrogenase subunit 4 & $\mathrm{G}>\mathrm{A}$ & non-syn:V-M & 1 & 0.0760 & \\
\hline 11253 & NADH dehydrogenase subunit 4 & $\mathrm{~T}>\mathrm{C}$ & non-syn:I-T & 4 & 0.0398 & 0.0069 \\
\hline 11711 & NADH dehydrogenase subunit 4 & $\mathrm{G}>\mathrm{A}$ & non-syn:A-T & 1 & 0.1110 & \\
\hline 11719 & NADH dehydrogenase subunit 4 & $\mathrm{G}>\mathrm{A}$ & syn:G-G & 1 & 0.0160 & \\
\hline 13368 & NADH dehydrogenase subunit 5 & $\mathrm{G}>\mathrm{A}$ & syn:G-G & 1 & 0.0130 & \\
\hline 13722 & NADH dehydrogenase subunit 5 & $A>G$ & syn:L-L & 10 & 0.1229 & 0.0453 \\
\hline 14160 & NADH dehydrogenase subunit 6 & $\mathrm{G}>\mathrm{A}$ & non-syn:R-W & 1 & 0.0940 & \\
\hline 15246 & Cytochrome b & $\mathrm{G}>\mathrm{A}$ & non-syn:G-D & 1 & 0.1140 & \\
\hline 16092 & Hypervariable segment 1 & $\mathrm{~T}>\mathrm{C}$ & - & 2 & 0.0410 & 0.0141 \\
\hline 16126 & Hypervariable segment 1 & $\mathrm{~T}>\mathrm{C}$ & - & 1 & 0.0170 & \\
\hline 16129 & Hypervariable segment 1 & $G>A$ & - & 1 & 0.2170 & \\
\hline 16294 & Hypervariable segment 1 & $\mathrm{C}>\mathrm{T}$ & - & 1 & 0.1160 & \\
\hline 16304 & Hypervariable segment 1 & $\mathrm{~T}>\mathrm{C}$ & - & 2 & 0.0395 & 0.0304 \\
\hline 16482 & Hypervariable segment 1 & $A>G$ & - & 1 & 0.0570 & \\
\hline
\end{tabular}

syn—synonymous mutation; non-syn—non-synonymous mutation. 


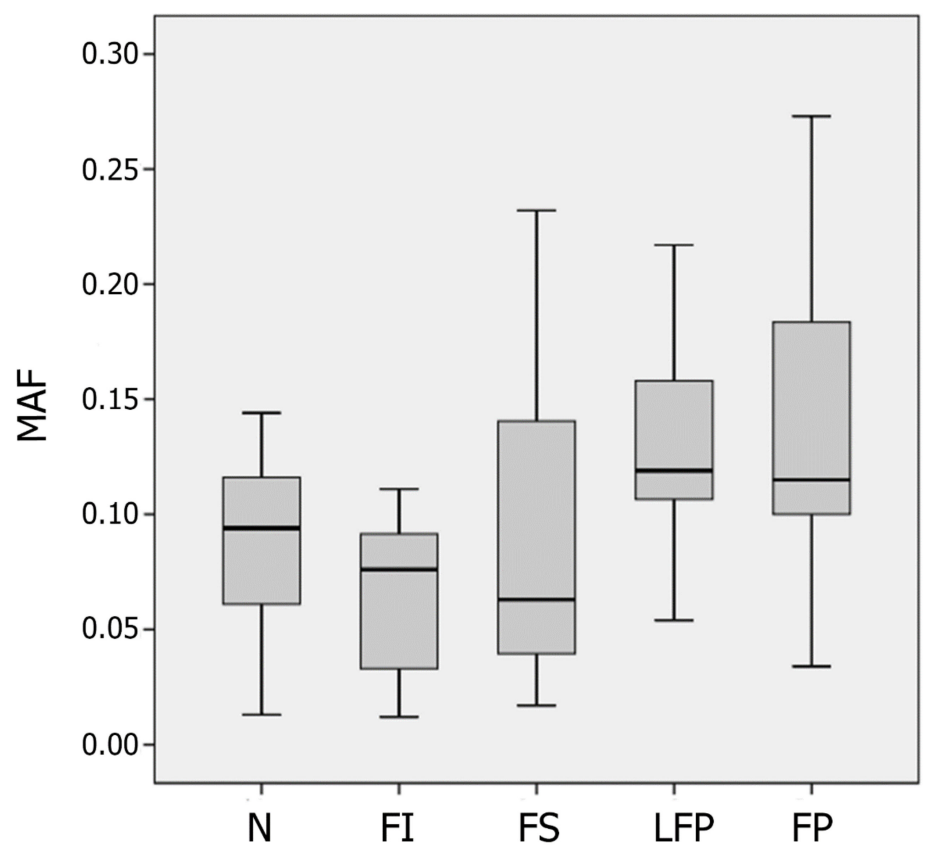

Figure 4. The boxplot showing the mean minor allele frequencies (MAF) values of heteroplasmic mtDNA variants in unaffected aortic intima $(\mathrm{N})$ and different types of atherosclerotic lesions (FI, fatty infiltration; FS, fatty streaks; LFP, lipofibrous plaque; FP, fibrous plaque).

Table 3. Contingency table for minor and major variants in heteroplasmic mutations.

\begin{tabular}{lccccc}
\hline \multirow{2}{*}{ Parameter } & \multicolumn{5}{c}{ The Type of Atherosclerotic Lesion } \\
\cline { 2 - 6 } & N & FI & FS & LFP & FP \\
\hline The number of minor variants & 68 & 70 & 106 & 113 & 134 \\
The number of major variants & 786 & 1049 & 965 & 732 & 801 \\
\hline
\end{tabular}

$\mathrm{N}$-normal (unaffected) intima; FI—fatty infiltration; FS—fatty streak; LFP—lipofibrous plaque; FP—fibrous plaque.

Table 4. Mean minor allele frequencies (MAF) values in unaffected (N) and atherosclerotic (FI, fatty infiltration; FS, fatty streaks; LFP, lipofibrous plaque; FP, fibrous plaque) aortic tissue samples.

\begin{tabular}{ccc}
\hline \multirow{2}{*}{ Case No. (ID) } & \multicolumn{2}{c}{ Mean MAF } \\
\cline { 2 - 3 } & N+FI & FS+FP+LFP \\
\hline as_01 & 0 & 0.115 \\
as_02 & 0.097 & 0.107 \\
as_03 & 0.074 & 0.133 \\
as_04 & 0.060 & 0.111 \\
as_05 & 0.098 & 0.136 \\
as_06 & 0.039 & 0.055 \\
as_07 & 0.019 & 0.211 \\
\hline
\end{tabular}

\subsection{MtDNA Copy Number}

Results of mtDNA copy number $(\mathrm{mtCN})$ measurements are presented in Table S2 (Supplementary Materials) and Figures 5 and 6. The data were normalized to an arbitrary sample (unaffected intima) in each case to provide a fold difference between samples. 


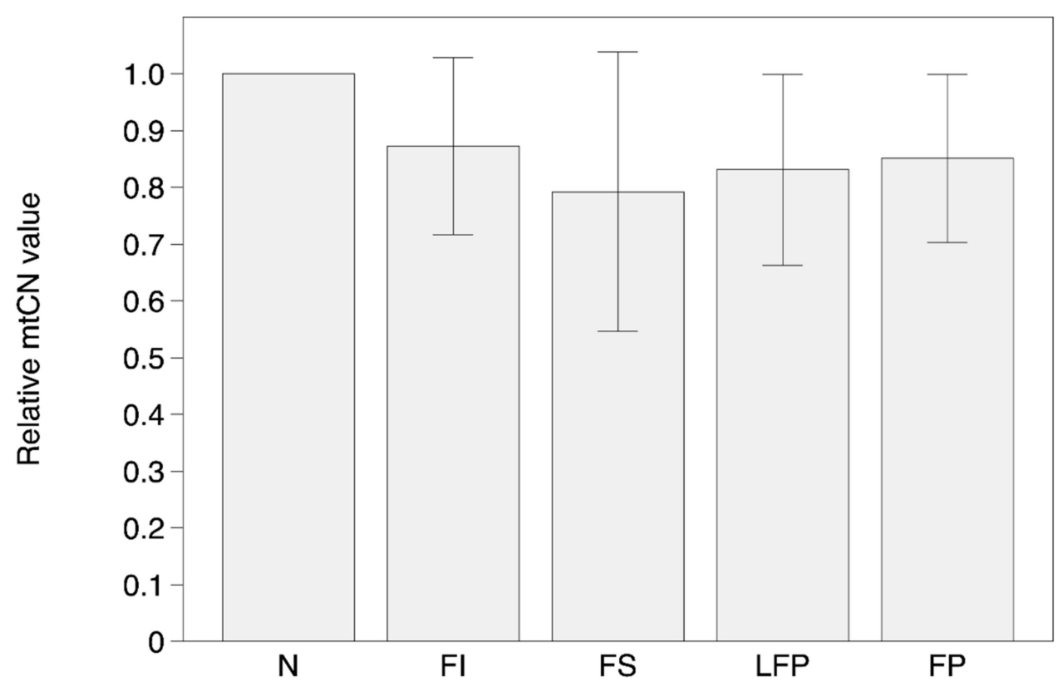

Figure 5. The relative $\mathrm{mtCN}$ values in unaffected aortic intima $(\mathrm{N})$ and different types of atherosclerotic lesions (FI, fatty infiltration; FS, fatty streaks; LFP, lipofibrous plaque; FP, fibrous plaque).

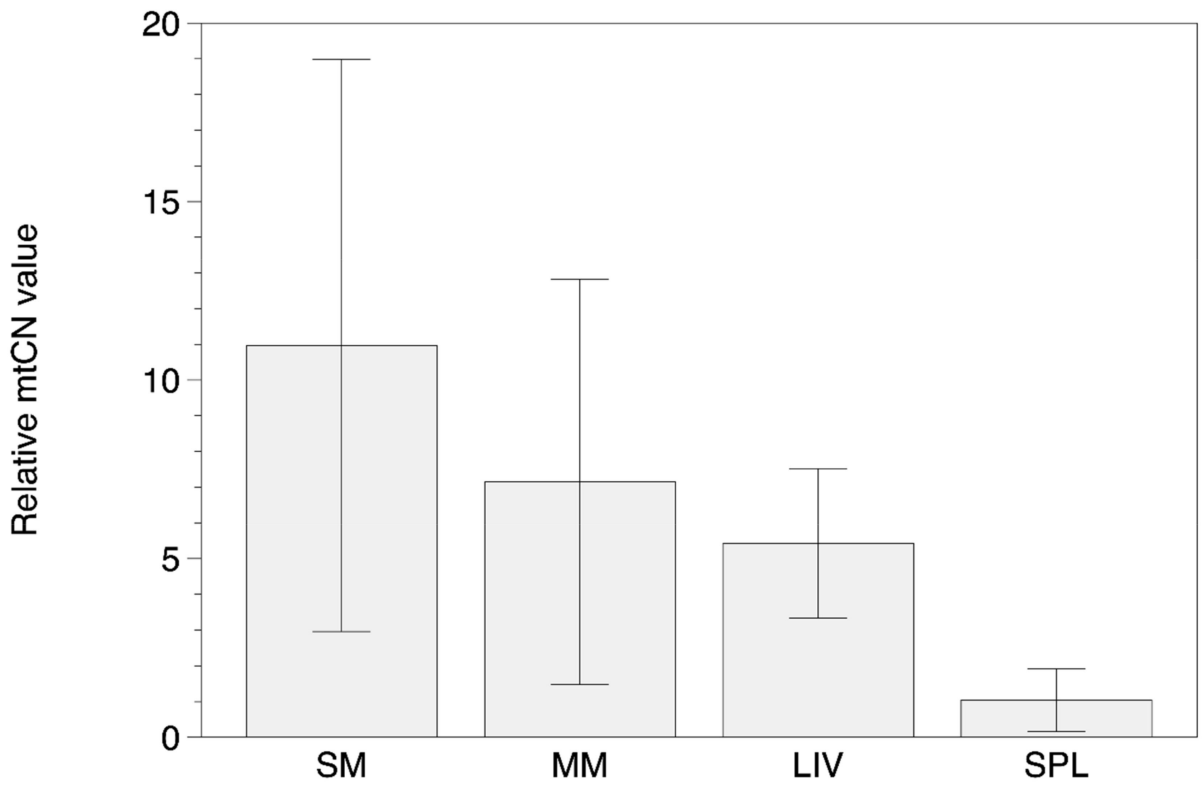

Figure 6. The relative MtDNA copy number $(\mathrm{mtCN})$ values in tissue samples from skeletal muscle (SM), myocardial muscle (MM), liver (LIV) and spleen (SPL).

In general, there were no significant differences in the $\mathrm{mtCNs}$ in the different types of atherosclerotic lesions of aortic intima. The overall $\mathrm{mtCN}$ distribution between $\mathrm{N}, \mathrm{FI}, \mathrm{FS}, \mathrm{FP}$, and LFP samples was similar among the majority of individuals: the MTCN values ranged 200-250 with CV no more than 25\% (Table S2 (Supplementary Materials), Figure 5). However, one sample (as_01) have demonstrated reduced $\mathrm{mtCN}$ values in aortic tissue, and one more sample (as_04) - the elevated values. The results of $\mathrm{mtCN}$ determination in another types of tissues showed clear differences in mean $\mathrm{mtCN}$ values with maximum in SM and minimum in SPL samples (Table S2 (Supplementary Materials), Figure 6).

\section{Discussion}

Our present findings showed that the presence of mtDNA heteroplasmic variants in unaffected and atherosclerotic intima of human aorta is a common phenomenon but lacking the obvious tendency. At least, none of the detected mtDNA variants could be described as lesion-specific one. Previously, several mtDNA heteroplasmic variants were reported to be associated with atherosclerotic lesions $[25,26,45]$. 
It is notable that pyrosequencing with short reads was mainly applied within those studies. Using another technique of amplification and sequencing, these variants were either not found in the similar types of samples, ore were filtered out at the stage of raw data analysis. Following the results of 454-sequencing, it may be assumed that mtDNA heteroplasmy can be found presumably in individual cases. Mean coverage of all heteroplasmic sites in our study was $80.3 \pm 57.2$; the mean MAF accounted for 0.09 , with $12 \%$ mean heteroplasmy level. The half of the observed cases of heteroplasmy had the coverage of more than 60 reads, and for these cases the lowest detectable heteroplasmy level accounted for 3\%, since the minimum of 2 reads (forward and reverse ones) was required for detection. Therefore, it may be assumed that the mtDNA variants with heteroplasmy level of 10-20\% would likely have been detected by 454-sequencing. A lack of compatibility between different studies is a challenging question that can be possibly solved by several explanations. There can be a bias in the amplification step of short reads in pyrosequencing method leading to the increase of detectable values of heteroplasmy level of mtDNA mutations that remain undetectable using 454-sequencing method. Furthermore, in short read pyrosequencing clean-up of target PCR-product after the amplification step is not performed, and erroneous heteroplasmy levels can possibly be detected if there is a presence of nuclear mtDNA pseudogenes (NUMTS) amplicons with the same size in the amplicon pool. With the use of long-range PCR prior to sequencing, target large mtDNA amplicons can be cleaned up from possibly occurring NUMTS short PCR products.

MtCN is now increasingly studied as a possible biomarker of aging and disease [46-48]. A number of studies were carried out to reveal the role of $\mathrm{mtCN}$ in atherosclerotic-related diseases and diabetes [11-14]. Chien et al. [49] have measured mtCN in human blood vessel tissue and have found that diabetic patients had significantly fewer copies of mtDNA than non-diabetic subjects, and patients with arterial stenosis had fewer copies compared to those without arterial stenosis. In our study we did not compare mtCN in patients with different severity of atherosclerosis, but our aim was to study the differences in $\mathrm{mtCN}$ relative values between different types of lesions in the same vessel. There was no significant increase or decrease in $\mathrm{mtCN}$, which could correspond to atherosclerosis progression from unaffected tissue to advanced atherosclerotic lesions. Although there were differences in $\mathrm{mtCN}$ distribution between different subjects, the most common distribution seemed to be without significant differences in $\mathrm{mtCN}$ of different lesion types. Some samples demonstrated lowered $\mathrm{mtCN}$ relative values in lesions compared to normal tissue, but there was no regularity of this trend in the general sample. Relying on these findings we can conclude that there is no exact evidence of increased mitochondria biogenesis as well as increased mitophagy or mitochondria elimination in atherosclerotic lesions compared to unaffected intima. MtCN of aortic intimal tissue was less than that in myocardial or skeletal muscle and liver tissue. Our results of mtCN measurements in different types of human tissues (SM, MM, LIV, and SPL) are well consistent with previously published data obtained by both qPCR and high-throughput sequencing [50,51].

Comparing our results with the massively parallel sequencing data on assessment of heteroplasmy across ten tissues obtained by Samuels at al. in 2013 [51], we found one match in heteroplasmic mutation (m.16126T > C) found in kidney and skeletal muscle with the quite similar MAF). Also, studying pathologically changed tissues, we have found more heteroplasmic variants in the coding region of $\mathrm{mtDNA}$, and some of them were missence mutations, located in cytochrome c oxidase and NADH-dehydrogenase subunits and cytochrome b genes. Some of these mutations (m.10686G $>$ A, m.11253T >C, m.14160G > A, and m.11711G > A) were previously described [52-57], but two variants were novel (m.7703T $>$ C and m.15246G > A). Interestingly, some of these missence heteroplasmic mutations were found in cancer tissues, what leads to suggestion of somatic nature of these mutations as a cause of changes in tissue microenviroment.

This study has several limitations. First, since the composition of cell types in human aortic intima is different in unaffected and atherosclerotic samples, it may be reliable to assume the influence on mtDNA copy number and mutational load. Earlier we have characterized the cell composition in unaffected and atherosclerotic intima (initial lesions, fatty streaks, lipofibrous plaques and fibrous 
plaques $[58,59]$. It was shown that all types of intimal samples contain smooth muscle cells containing smooth muscle $\alpha$-actin (approximately $50 \%$ of total cell population), the cells of hematogenic origin (lymphocytes and macrophages, from $3 \%$ to $20 \%$ of total cell population), and pericyte-like cells (from $30 \%$ to $40 \%$ of total cell population). More, pericyte-like cells in unaffected and atherosclerotic aortic intima are characterized by lowered proportion of resting cells in initial lesions and fatty streaks, and the increased proportion of activated cells in lipofibrous and fibrous plaques [60]. One should also consider the fact of simultaneous expression of macrophage antigen by subendothelial smooth muscle cells [61]. Such characteristics of cellular composition, along with technical problems of isolation of alive specific cell types from subendothelial intima for further DNA isolation, make the estimation of their influence on mtDNA copy number and mutational load a real challenge. Next, the comparative ct method used for mtCN estimation does not allow for absolute copy number count like standard curve method; all possible mtDNA deletions could not necessarily be caught with next generation sequencing depending on the criteria used to throw out reads. Finally, the sample size was small (all intimal samples were obtained from 7 autopsy cases, 4 males and 3 females), it was impossible to make statistically valid estimates of the distribution of heteroplasmic variants across individuals, of the difference between male and female individuals, on the overlap between heteroplasmic variants and known haplogroup motifs, on the association between age and mtDNA variants, etc. Although the same heteroplasmic variants were usually found in the replicates of the same types of atherosclerotic lesions within the same autopsy sample, statistical estimate of conservation was impossible as well, since there was maximum of $2-3$ replicates per specific sample.

\section{Conclusions}

The main finding in this study was the progressive increase in the number of occurring heteroplasmic mtDNA variants from normal (non-atherosclerotic) intima to advanced lesions, like lipofibrous and fibrous plaques. Therefore, the possibility of somatic origin of mtDNA heteroplasmic variants due to the increased ROS production and impaired mitochondrial function supports the hypothesis of accumulation of mutant mtDNA copies during atherogenesis. Basing on the ratio of minor and major nucleotide mtDNA variants, we can conclude that there exists the increase in the number of heteroplasmic mtDNA variants, which corresponds to the extent of atherosclerotic morphologic phenotype. The accumulating global data on the mtDNA damage in atherosclerosis $[62,63]$ make this hypothesis plausible, taking in account the role of increased oxidative stress as the mechanistic factor of atherosclerotic risk. However, oxidative stress cannot be considered as the main mechanism of origination of mtDNA somatic mutations. The results of the recent studies argue against oxidative damage hypothesis [64,65], and suggest, for example, that replication errors by DNA polymerase $\gamma$ and/or spontaneous base hydrolysis may be more responsible for accumulation of mtDNA point mutations [66]. The nature of pathogenic and mechanistic role of heteroplasmic mtDNA variants in the development of disease phenotype is far from understanding. It is even not possible to consider them as the causation or the consequence of pathology. To answer this fundamental question, it is necessary to study the functional consequences of mitochondrial site-specific DNA damage. The use of cell-based models seems to be a promising way; for example, cytoplasmic hybrids (cybrids) are currently among the best for the study of mitochondrial dysfunction, although this model has certain disadvantages [67]. Another and possibly better approach is aimed to the direct editing of mtDNA for the precise studies of the effects of single nucleotide substitution [68]; however, direct modification of the mitochondrial genome is not yet technically solved scientific and technical problem, because there is still no reliable way of delivering nucleic acids and molecular structures to the mitochondria of living cells $[69,70]$. In any way, the disclosure of associations between mtDNA damage and pathology will provide new knowledge of atherogenesis as the age-related degenerative disease process and build the basis for developing new approaches to diagnosis, prevention and treatment. 
Supplementary Materials: The following are available online at http://www.mdpi.com/2218-273X/9/9/455/s1, Table S1: MAF values for heteroplasmic mtDNA variants found in the aortic intimal tissue, Table S2: Relative $\mathrm{mtCN}$ values in the observed tissue samples.

Author Contributions: Conceptualization, I.A.S., V.J.M. and A.N.O.; Data curation, I.A.S., A.V.Z., V.J.M. and A.Y.P.; Formal analysis, A.V.Z., L.V.M., M.O.S. and V.J.M.; Funding acquisition, I.A.S.; Investigation, A.V.Z., Z.B.K., V.V.S., K.I.K., A.S.S. and V.N.S.; Methodology, I.A.S., A.V.Z. and Z.B.K.; Project administration, I.A.S.; Resources, A.Y.P. and A.V.G.; Supervision, I.A.S., A.Y.P., A.V.G. and A.N.O.; Writing-original draft, I.A.S. and A.V.Z.; Writing一revised paper, I.A.S. and A.Y.P.

Funding: This research and the APC were funded by Russian Science Foundation, grant number 19-15-00297.

Acknowledgments: The authors thank Anastasia Ryzhkova for technical assistance in preparation of «Shotgun» DNA libraries.

Conflicts of Interest: The authors declare no conflict of interest. The funders had no role in the design of the study; in the collection, analyses, or interpretation of data; in the writing of the manuscript, or in the decision to publish the results. Partial results of this study have been previously reported as a poster presentation at International Atherosclerosis Society Symposium (9-12 June 2018, Toronto, ON, Canada).

\section{References}

1. Cheng, C.; Tempel, D.; van Haperen, R.; van der Baan, A.; Grosveld, F.; Daemen, M.J.; Krams, R.; de Crom, R. Atherosclerotic lesion size and vulnerability are determined by patterns of fluid shear stress. Circulation 2006, 113, 2744-2753. [CrossRef]

2. Lehoux, S.; Castier, Y.; Tedgui, A. Molecular mechanisms of the vascular responses to haemodynamic forces. J. Intern. Med. 2006, 259, 381-392. [CrossRef]

3. Chistiakov, D.A.; Sobenin, I.A.; Orekhov, A.N.; Bobryshev, Y.V. Dendritic cells: A double-edge sword in atherosclerotic inflammation. Curr. Pharm. Des. 2015, 21, 1118-1123. [CrossRef]

4. Chistiakov, D.A.; Sobenin, I.A.; Revin, V.V.; Orekhov, A.N.; Bobryshev, Y.V. Mitochondrial aging and age-related dysfunction of mitochondria. Biomed. Res. Int. 2014, 2014, 238463. [CrossRef]

5. Madamanchi, N.R.; Runge, M.S. Mitochondrial dysfunction in atherosclerosis. Circ. Res. 2007, 100, 460-473. [CrossRef]

6. Hulsmans, M.; van Dooren, E.; Holvoet, P. Mitochondrial reactive oxygen species and risk of atherosclerosis. Curr. Atheroscler. Rep. 2012, 14, 264-276. [CrossRef]

7. Chinnery, P.F.; Hudson, G. Mitochondrial genetics. Br. Med. Bull. 2013, 106, 135-159. [CrossRef]

8. Just, R.S.; Irwin, J.A.; Parson, W. Mitochondrial DNA heteroplasmy in the emerging field of massively parallel sequencing. Forensic. Sci. Int. Genet. 2015, 18, 131-139. [CrossRef]

9. Palculict, M.E.; Zhang, V.W.; Wong, L.J.; Wang, J. Comprehensive mitochondrial genome analysis by massively parallel sequencing. Methods Mol. Biol. 2016, 1351, 3-17. [CrossRef]

10. Li, M.; Schröder, R.; Ni, S.; Madea, B.; Stoneking, M. Extensive tissue-related and allele-related mtDNA heteroplasmy suggests positive selection for somatic mutations. Proc. Natl. Acad. Sci. USA 2015, 112, 2491-2496. [CrossRef]

11. Chen, S.; Xie, X.; Wang, Y.; Gao, Y.; Xie, X.; Yang, J.; Ye, J. Association between leukocyte mitochondrial DNA content and risk of coronary heart disease: A case-control study. Atherosclerosis 2014, 237, 220-226. [CrossRef]

12. Ashar, F.N.; Zhang, Y.; Longchamps, R.J.; Lane, J.; Moes, A.; Grove, M.L.; Mychaleckyj, J.C.; Taylor, K.D.; Coresh, J.; Rotter, J.I.; et al. Association of mitochondrial DNA copy number with cardiovascular disease. JAMA Cardiol. 2017, 2, 1247-1255. [CrossRef]

13. Zhang, Y.; Guallar, E.; Ashar, F.N.; Longchamps, R.J.; Castellani, C.A.; Lane, J.; Grove, M.L.; Coresh, J.; Sotoodehnia, N.; Ilkhanoff, L.; et al. Association between mitochondrial DNA copy number and sudden cardiac death: Findings from the Atherosclerosis Risk in Communities study (ARIC). Eur. Heart J. 2017, 38, 3443-3448. [CrossRef]

14. Liu, L.P.; Cheng, K.; Ning, M.A.; Li,H.H.; Wang, H.C.; Li, F.; Chen, S.Y.; Qu, F.L.; Guo, W.Y. Association between peripheral blood cells mitochondrial DNA content and severity of coronary heart disease. Atherosclerosis 2017, 261, 105-110. [CrossRef]

15. Greaves, L.C.; Reeve, A.K.; Taylor, R.W.; Turnbull, D.M. Mitochondrial DNA and disease. J. Pathol. 2012, 6, 274-286. [CrossRef] 
16. Lombès, A.; Auré, K.; Bellanné-Chantelot, C.; Gilleron, M.; Jardel, C. Unsolved issues related to human mitochondrial diseases. Biochimie 2014, 100, 171-176. [CrossRef]

17. Wallace, D.C. Mitochondria and cancer. Nat. Rev. Cancer 2012, 12, 685-698. [CrossRef]

18. Ye, K.; Lu, J.; Ma, F.; Keinan, A.; Gu, Z. Extensive pathogenicity of mitochondrial heteroplasmy in healthy human individuals. Proc. Natl. Acad. Sci. USA 2014, 111, 10654-10659. [CrossRef]

19. Fernández-Vizarra, E.; Enríquez, J.A.; Pérez-Martos, A.; Montoya, J.; Fernández-Silva, P. Tissue-specific differences in mitochondrial activity and biogenesis. Mitochondrion 2011, 11, 207-213. [CrossRef]

20. Li, M.; Rothwell, R.; Vermaat, M.; Wachsmuth, M.; Schröder, R.; Laros, J.F.; van Oven, M.; de Bakker, P.I.; Bovenberg, J.A.; van Duijn, C.M.; et al. Transmission of human mtDNA heteroplasmy in the Genome of the Netherlands families: Support for a variable-size bottleneck. Genome Res. 2016, 26, 417-426. [CrossRef]

21. Sobenin, I.A.; Chistiakov, D.A.; Bobryshev, Y.V.; Postnov, A.Y.; Orekhov, A.N. Mitochondrial mutations in atherosclerosis: New solutions in research and possible clinical applications. Curr. Pharm. Des. 2013, 19, 5942-5953. [CrossRef]

22. Sobenin, I.A.; Mitrofanov, K.Y.; Zhelankin, A.V.; Sazonova, M.A.; Postnov, A.Y.; Revin, V.V.; Bobryshev, Y.V.; Orekhov, A.N. Quantitative assessment of heteroplasmy of mitochondrial genome: Perspectives in diagnostics and methodological pitfalls. Biomed. Res. Int. 2014, 2014, 292017. [CrossRef]

23. Jenuth, J.P.; Peterson, A.C.; Shoubridge, E.A. Tissue-specific selection for different mtDNA genotypes in heteroplasmic mice. Nat. Genet. 1997, 16, 93-95. [CrossRef]

24. Stewart, J.B.; Freyer, C.; Elson, J.L.; Larsson, N.G. Purifying selection of mtDNA and its implications for understanding evolution and mitochondrial disease. Nat. Rev. Genet. 2008, 9, 657-662. [CrossRef]

25. Sazonova, M.A.; Sinyov, V.V.; Barinova, V.A.; Ryzhkova, A.I.; Zhelankin, A.V.; Postnov, A.Y.; Sobenin, I.A.; Bobryshev, Y.V.; Orekhov, A.N. Mosaicism of mitochondrial genetic variation in atherosclerotic lesions of the human aorta. Biomed. Res. Int. 2015, 2015, 825468. [CrossRef]

26. Sobenin, I.A.; Sazonova, M.A.; Postnov, A.Y.; Bobryshev, Y.V.; Orekhov, A.N. Changes of mitochondria in atherosclerosis: Possible determinant in the pathogenesis of the disease. Atherosclerosis 2013, 227, 283-288. [CrossRef]

27. Li, M.; Schönberg, A.; Schaefer, M.; Schroeder, R.; Nasidze, I.; Stoneking, M. Detecting heteroplasmy from high-throughput sequencing of complete human mitochondrial DNA genomes. Am. J. Hum. Genet. 2010, 87, 237-249. [CrossRef]

28. Payne, B.A.; Wilson, I.J.; Yu-Wai-Man, P.; Coxhead, J.; Deehan, D.; Horvath, R.; Taylor, R.W.; Samuels, D.C.; Santibanez-Koref, M.; Chinnery, P.F. Universal heteroplasmy of human mitochondrial DNA. Hum. Mol. Genet. 2013, 22, 384-390. [CrossRef]

29. Stary, H.C.; Chandler, A.B.; Glagov, S.; Guyton, J.R.; Insull, W., Jr.; Rosenfeld, M.E.; Schaffer, S.A.; Schwartz, C.J.; Wagner, W.D.; Wissler, R.W. A definition of initial, fatty streak, and intermediate lesions of atherosclerosis. A report from the Committee on Vascular Lesions of the Council on Arteriosclerosis, American Heart Association. Circulation 1994, 89, 2462-2478. [CrossRef]

30. Stary, H.C.; Chandler, A.B.; Dinsmore, R.E.; Fuster, V.; Glagov, S.; Insull, W., Jr.; Rosenfeld, M.E.; Schwartz, C.J.; Wagner, W.D.; Wissler, R.W. A definition of advanced types of atherosclerotic lesions and a histological classification of atherosclerosis. A report from the Committee on Vascular Lesions of the Council on Arteriosclerosis, American Heart Association. Circulation 1995, 92, 1355-1374. [CrossRef]

31. Venegas, V.; Halberg, M.C. Measurement of mitochondrial DNA copy number. Methods Mol. Biol. 2012, 837, 327-335. [CrossRef]

32. Schmittgen, T.D.; Livak, K.J. Analyzing real-time PCR data by the comparative $\mathrm{C}_{\mathrm{T}}$ method. Nat. Protoc. 2008, 3, 1101-1108. [CrossRef]

33. Mikkelsen, M.; Frank-Hansen, R.; Hansen, A.J.; Morling, N. Massively parallel pyrosequencing of the mitochondrial genome with the 454 methodology in forensic genetics. Forensic. Sci. Int. Genet. 2014, 12, 30-37. [CrossRef]

34. Martin, M. Cutadapt removes adapter sequences from high-throughput sequencing reads. EMBnet. J. 2011, 17, 10-12. [CrossRef]

35. Bolger, A.M.; Lohse, M.; Usadel, B. Trimmomatic: A flexible trimmer for Illumina sequence data. Bioinformatics 2014, 30, 2114-2120. [CrossRef]

36. Homo Sapiens Mitochondrion, Complete Genome. NCBI Reference Sequence: NC_012920.1. Available online: https://www.ncbi.nlm.nih.gov/nuccore/NC_012920.1?report=fasta\&to=16569. (accessed on 20 August 2019). 
37. Li, H. Aligning sequence reads, clone sequences and assembly contigs with BWA-MEM. arXiv 2013, arXiv:1303.3997v2 [q-bio.GN].

38. Li, H. A statistical framework for SNP calling, mutation discovery, association mapping and population genetical parameter estimation from sequencing data. Bioinformatics 2011, 27, 2987-2993. [CrossRef]

39. Wang, K.; Li, M.; Hakonarson, H. ANNOVAR: Functional annotation of genetic variants from high-throughput sequencing data. Nucleic Acids Res. 2010, 38, e164. [CrossRef]

40. Jones, E.; Oliphant, T.; Peterson, P. SciPy: Open Source Scientific Tools for Python. 2001. Available online: http://www.scipy.org (accessed on 30 June 2019).

41. McKinney, W. Data structures for statistical computing in python. In Proceedings of the 9th Python in Science Conference, Austin, TX, USA, 28 June-3 July 2010; van der Walt, S., Millman, J., Eds.; SciPy: Austin, TX, USA; pp. 51-56.

42. Hunter, J.D. Matplotlib: A 2D Graphics Environment. Comput. Sci. Eng. 2007, 9, 90-95. [CrossRef]

43. Waskom, M.; Botvinnik, O.; O' Kane, D.; Hobson, P.; Ostblom, J.; Lukauskas, S.; Gemperline, D.C.; Augspurger, T.; Halchenko, Y.; Cole, J.B.; et al. Mwaskom/Seaborn: v0.9.0 (July 2018); Zenodo: Geneva, Switzerland, 2018. [CrossRef]

44. den Dunnen, J.T. Describing sequence variants using HGVS nomenclature. Methods Mol. Biol. 2017, 1492, 243-251. [CrossRef]

45. Sobenin, I.A.; Sazonova, M.A.; Postnov, A.Y.; Bobryshev, Y.V.; Orekhov, A.N. Mitochondrial mutations are associated with atherosclerotic lesions in the human aorta. Clin. Dev. Immunol. 2012, 2012, 832464. [CrossRef]

46. Wachsmuth, M.; Huebner, A.; Li, M.; Madea, B.; Stoneking, M. Age-related and heteroplasmy-related variation in human mtDNA copy number. PLoS Genet. 2016, 12, e1005939. [CrossRef]

47. van Osch, F.H.; Voets, A.M.; Schouten, L.J.; Gottschalk, R.W.; Simons, C.C.; van Engeland, M.; Lentjes, M.H.; van den Brandt, P.A.; Smeets, H.J.; Weijenberg, M.P. Mitochondrial DNA copy number in colorectal cancer: Between tissue comparisons, clinicopathological characteristics and survival. Carcinogenesis 2015, 36, 1502-1510. [CrossRef]

48. Wang, Y.C.; Lee, W.C.; Liao, S.C.; Lee, L.C.; Su, Y.J.; Lee, C.T.; Chen, J.B. Mitochondrial DNA copy number correlates with oxidative stress and predicts mortality in nondiabetic hemodialysis patients. J. Nephrol. 2011, 24, 351-358. [CrossRef]

49. Chien, M.C.; Huang, W.T.; Wang, P.W.; Liou, C.W.; Lin, T.K.; Hsieh, C.J.; Weng, S.W. Role of mitochondrial DNA variants and copy number in diabetic atherogenesis. Genet. Mol. Res. 2012, 11, 3339-3348. [CrossRef]

50. Miller, F.J.; Rosenfeldt, F.L.; Zhang, C.; Linnane, A.W.; Nagley, P. Precise determination of mitochondrial DNA copy number in human skeletal and cardiac muscle by a PCR-based assay: Lack of change of copy number with age. Nucleic Acids Res. 2003, 31, e61. [CrossRef]

51. Samuels, D.; Li, C.; Li, B.; Song, Z.; Torstenson, E.; Boyd Clay, H.; Rokas, A.; Thornton-Wells, T.A.; Moore, J.H.; Hughes, T.M.; et al. Recurrent tissue-specific mtDNA mutations are common in humans. PLoS Genet. 2013, 9, e1003929. [CrossRef]

52. Hofmann, S.; Jaksch, M.; Bezold, R.; Mertens, S.; Aholt, S.; Paprotta, A.; Gerbitz, K.D. Population genetics and disease susceptibility: Characterization of central European haplogroups by mtDNA gene mutations, correlation with D loop variants and association with disease. Hum. Mol. Genet. 1997, 6, 1835-1846. [CrossRef]

53. Jeronimo, C.; Nomoto, S.; Caballero, O.L.; Usadel, H.; Henrique, R.; Varzim, G.; Oliveira, J.; Lopes, C.; Fliss, M.S.; Sidransky, D. Mitochondrial mutations in early stage prostate cancer and bodily fluids. Oncogene 2001, 20, 5195-5198. [CrossRef]

54. Zaki, E.A.; Freilinger, T.; Klopstock, T.; Baldwin, E.E.; Heisner, K.R.; Adams, K.; Dichgans, M.; Wagler, S.; Boles, R.G. Two common mitochondrial DNA polymorphisms are highly associated with migraine headache and cyclic vomiting syndrome. Cephalalgia 2009, 29, 719-728. [CrossRef]

55. Alvarez-Iglesias, V.; Mosquera-Miguel, A.; Cerezo, M.; Quintans, B.; Zarrabeitia, M.T.; Cusco, I.; Lareu, M.V.; García, O.; Pérez-Jurado, L.; Carracedo, A.; et al. New population and phylogenetic features of the internal variation within mitochondrial DNA macro-haplogroup R0. PLoS ONE 2009, 4, e5112. [CrossRef]

56. Wong, L.J.; Liang, M.H.; Kwon, H.; Park, J.; Bai, R.K.; Tan, D.J. Comprehensive scanning of the entire mitochondrial genome for mutations. Clin. Chem. 2002, 48, 1901-1912.

57. Ericson, N.G.; Kulawiec, M.; Vermulst, M.; Sheahan, K.; O’Sullivan, J.; Salk, J.J.; Bielas, J.H. Decreased mitochondrial DNA mutagenesis in human colorectal cancer. PLoS Genet. 2012, 8, e1002689. [CrossRef] 
58. Orekhov, A.N.; Andreeva, E.R.; Andrianova, I.V.; Bobryshev, Y.V. Peculiarities of cell composition and cell proliferation in different type atherosclerotic lesions in carotid and coronary arteries. Atherosclerosis 2010, 212, 436-443. [CrossRef]

59. Bobryshev, Y.V.; Andreeva, E.R.; Mikhailova, I.A.; Andrianova, I.V.; Moisenovich, M.M.; Khapchaev, S.; Agapov, I.I.; Sobenin, I.A.; Lusta, K.A.; Orekhov, A.N. Correlation between lipid deposition, immune-inflammatory cell content and MHC class II expression in diffuse intimal thickening of the human aorta. Atherosclerosis 2011, 219, 171-183. [CrossRef]

60. Summerhill, V.; Orekhov, A. Pericytes in atherosclerosis. Adv. Exp. Med. Biol. 2019, 1147, 279-297. [CrossRef]

61. Andreeva, E.R.; Pugach, I.M.; Orekhov, A.N. Subendothelial smooth muscle cells of human aorta express macrophage antigen in situ and in vitro. Atherosclerosis 1997, 135, 19-27. [CrossRef]

62. Yu, E.P.; Bennett, M.R. Mitochondrial DNA damage and atherosclerosis. Trends Endocrinol. Metab. 2014, 25, 481-487. [CrossRef]

63. Sinyov, V.V.; Sazonova, M.A.; Ryzhkova, A.I.; Galitsyna, E.V.; Melnichenko, A.A.; Postnov, A.Y.; Orekhov, A.N.; Grechko, A.V.; Sobenin, I.A. Potential use of buccal epithelium for genetic diagnosis of atherosclerosis using mtDNA mutations. Vessel Plus 2017, 1, 145-150. [CrossRef]

64. Trifunovic, A.; Hansson, A.; Wredenberg, A.; Rovio, A.T.; Dufour, E.; Khvorostov, I.; Spelbrink, J.N.; Wibom, R.; Jacobs, H.T.; Larsson, N.G. Somatic mtDNA mutations cause aging phenotypes without affecting reactive oxygen species production. Proc. Natl. Acad. Sci. USA 2005, 102, 17993-17998. [CrossRef]

65. Itsara, L.S.; Kennedy, S.R.; Fox, E.J.; Yu, S.; Hewitt, J.J.; Sanchez-Contreras, M.; Cardozo-Pelaez, F.; Pallanck, L.J. Oxidative stress is not a major contributor to somatic mitochondrial DNA mutations. PLoS Genet. 2014, 10, e1003974. [CrossRef]

66. Kennedy, S.R.; Salk, J.J.; Schmitt, M.W.; Loeb, L.A. Ultra-sensitive sequencing reveals an age-related increase in somatic mitochondrial mutations that are inconsistent with oxidative damage. PLoS Genet. 2013, 9, e1003794. [CrossRef]

67. Sazonova, M.A.; Sinyov, V.V.; Ryzhkova, A.I.; Galitsyna, E.V.; Melnichenko, A.A.; Postnov, A.Y.; Orekhov, A.N.; Sobenin, I.A. Cybrid models of pathological cell processes in different diseases. Oxid. Med. Cell Longev. 2018, 2018, 4647214. [CrossRef]

68. Sazonova, M.A.; Ryzhkova, A.I.; Sinyov, V.V.; Sazonova, M.D.; Khasanova, Z.B.; Nikitina, N.A.; Karagodin, V.P.; Orekhov, A.N.; Sobenin, I.A. Creation of cultures containing mutations linked with cardiovascular diseases using transfection and genome editing. Curr. Pharm. Des. 2019, 25, 693-699. [CrossRef]

69. Zhang, E.; Zhang, C.; Su, Y.; Cheng, T.; Shi, C. Newly developed strategies for multifunctional mitochondria-targeted agents in cancer therapy. Drug Discov. Today 2011, 16, 140-146. [CrossRef]

70. Fogleman, S.; Santana, C.; Bishop, C.; Miller, A.; Capco, D.G. CRISPR/Cas9 and mitochondrial gene replacement therapy: Promising techniques and ethical considerations. Am. J. Stem. Cells 2016, 5, 39-52. 